\title{
EFC Activity: Highlights 2020
}

by Dr. Hélène ILLAIRE, EFC Managing Officer

The European Federation of Corrosion (EFC) amalgamates Associations and Companies in Europe and beyond with common interests in corrosion. Its aim is to advance the science of corrosion and protection of materials by promoting cooperation in Europe and collaboration internationally. In January 2020, the EFC counted 38 member organisations (Member Societies and Affiliate Members), representing the corrosion interests of more than 25,000 engineers and scientists.

The EFC is proud to present below some highlights of its activities during the year 2020, and will continue to promote the interests of its members in 2021 and beyond.

\section{ELECTIONS}

From January $1^{\text {st }} 2021$, succeeding Prof. Arjan Mol, Dr. Jörg Vogelsang, from the company Sika Technology AG in Zürich is taking the Presidency of the Federation. The EFC team sincerely thanks Prof. Arjan Mol for his 2 years of fruitful and intensive work at the head of EFC, and warmly welcomes Dr. Jörg Vogelsang in to fulfil his mandate. We also welcome Prof. Tomáš Prošek, from the University of Chemistry and Technology in Prague (Czech Republic) as the new EFC Vice-President.

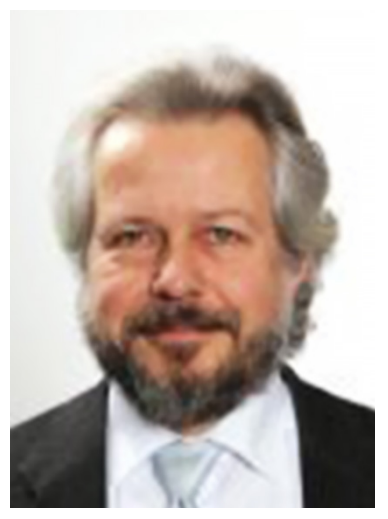

Dr. Jörg Vogelsang EFC President from $1^{\text {st }}$ of January

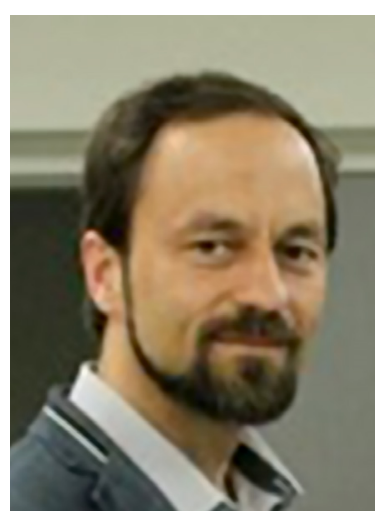

Prof. Tomáš Prošek EFC Vice-President from $1^{\text {st }}$ of January

\section{EUROCORR}

The EFC demonstrated its capability to organise successful online events with the virtual EUROCORR organised on 7-11 September. The virtual EUROCORR gathered about 600 people who were able to attend nearly 400 lectures given in 8 parallel sessions. The lectures were available online to registered participants until the end of November.

The physical EUROCORR event in Brussels, cancelled due to the Covid-19 crisis, is postponed to 2023 .

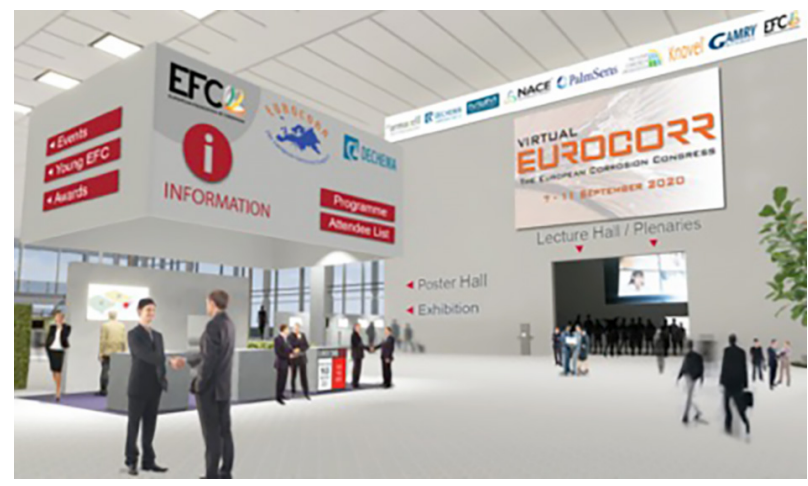

The virtual EUROCORR hall

\section{EFC Awards}

Several corrosionists were presented with awards by the EFC during virtual EUROCORR 2020, and the EFC congratulates especially:

- Professor Stuart Lyon (United Kingdom), who was awarded the European Corrosion Medal;

- Doctor Phillipe Dillman (France) who was awarded Honorary Fellowship of the EFC;

- Professor Fabrizio Zucchi (Italy), who was awarded the Cavallaro Medal selected by the University of Ferrara. 


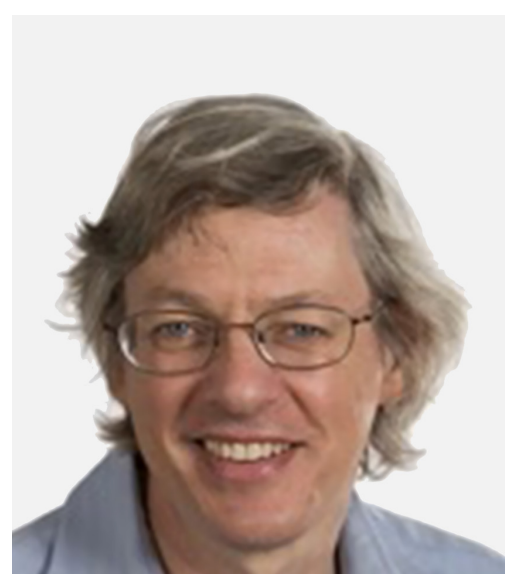

Prof. Stuart Lyon

recipient of the European Corrosion Medal

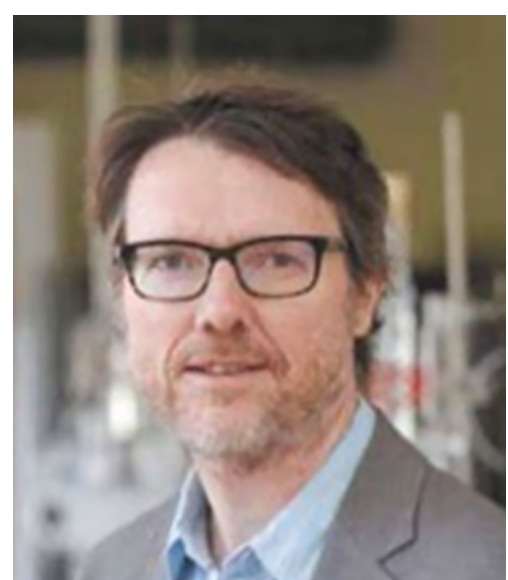

Dr. Phillipe Dillman

recipient of the Honorary Fellowship of the EFC

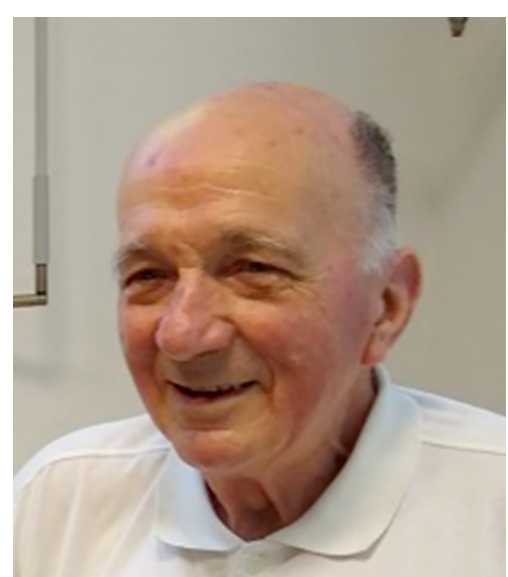

Prof. Fabrizio Zucchi

recipient of the Cavallaro Medal

Other awards delivered during EUROCORR include the Best Poster Award, the Best Presentation Award and the EUROCORR Young Scientist Grant Award. The names of the winners, as well as the recorded lecture of Prof. Lyon, can be found on the EFC website.

\section{Publications}

Two new books in the EFC book series were published in August 2020.:

- "Nuclear corrosion: research, progress and challenges", was edited by the EFC Working Party 4 "Nuclear Corrosion" under the lead of Stefan Ritter.

- The third edition of "Corrosion Under Insulation (CUI) guidelines" provides revised and updated technical guidance on managing CUI provided by EFC Working Parties 13 (Corrosion in Oil and Gas production) and 15 (Corrosion in the Refinery and Petrochemistry industry), under the lead of Gino De Landtsheer.

EFC members receive a $30 \%$ discount on all EFC publications when ordering via the Elsevier store.

\section{Scientific activities}

The EFC accomplishes its most important activities through its Working Parties and Task Forces devoted to various aspects of corrosion and its prevention. Besides publications and the organization of EUROCORR sessions, Working Parties regularly organize events, such as the two well attended EFC Web-Seminars on "Corrosion Protection by Organic Coatings" and on "Nuclear Corrosion" held in May and June 2020, respectively. Also, a new Working Party "Atmospheric Corrosion" has been created, under the lead of Prof. Tomáš Prošek. 


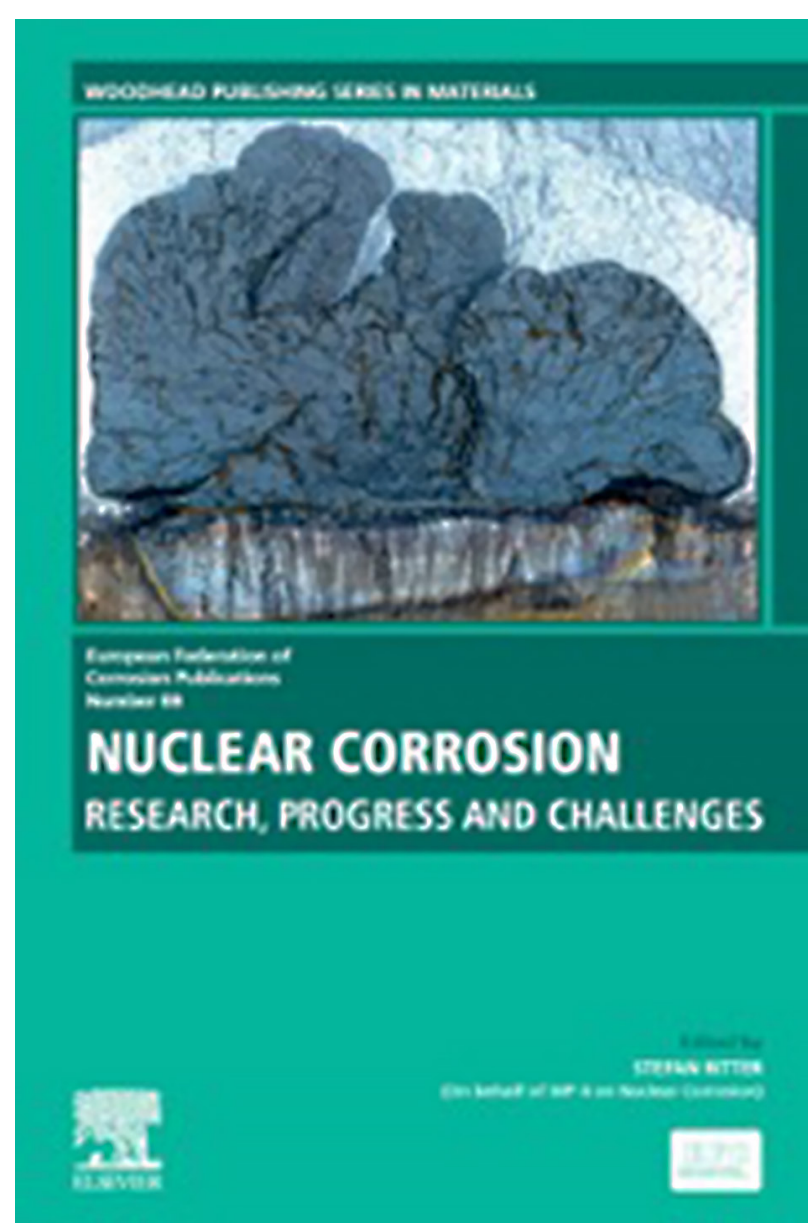

The new EFC book $n^{\circ} 55$, third edition

\section{EFC DIGITAL}

The EFC has improved its presence and visibility online with a new website launched in the May 2020. This website offers EFC individual members the possibility to login and receive news related to the specific areas of interest which they indicate.
The EFC is now also present on LinkedIn on which two pages have been created: the EFC official company page, where events and news are regularly published, and the group of EFC discussion page, where members of the corrosion community can exchange information particularly on scientific and technical subjects.

\section{Young EFC}

The Young EFC, beside its strong involvement in the Corrosion Awareness Day on $24^{\text {th }}$ April 2020, proposes actions to support the community of young corrosionists. Activities of the Young EFC in 2020 include a mentoring programme, the organisation of a free webinar on "How to write a paper" by Prof. Arjan Mol to be held on 20 January 2021, as well as the promotion of gender equality by giving more visibility to women researching in corrosion. More information and registration to these activities is available on the EFC website.

\section{Membership}

The special offer including Affiliate Membership and an exhibition booth at EUROCORR was popular in 2020 and is thus renewed for EUROCORR 2021, together with the Loyalty Programme for exhibitors. The deadline for joining these programmes is set on 28 February 2021. More information is available on the EFC website.

\section{Corrosion awareness day}

The 2020 edition of the Corrosion Awareness Day on $24^{\text {th }}$ April was strongly supported by the Young EFC who invited young researchers to actively take part in online actions related to Corrosion Science and Engineering on or around $24^{\text {th }}$ of April. These activities included a photo competition, dissemination articles and videos, free courses and webinars, all organized by students, societies and companies affiliated to the EFC. A summary of these many activities is provided online on the EFC website. There was also a successful WebSeminar on Low Carbon Technologies organised by the World Corrosion Organisation (WCO).

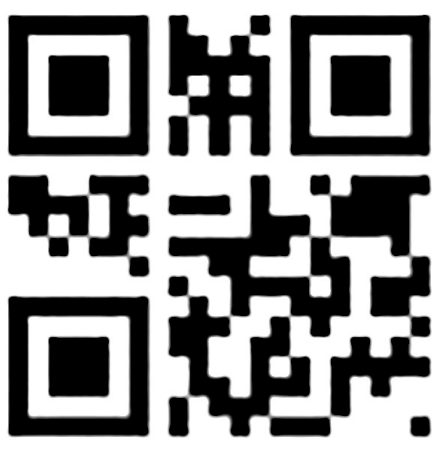

Flashcode to the EFC website

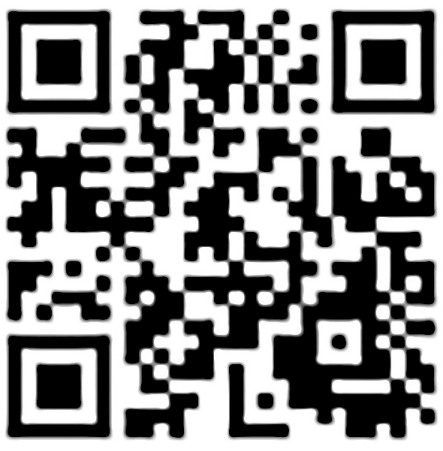

Flashcode to the EFC Linkedln company page

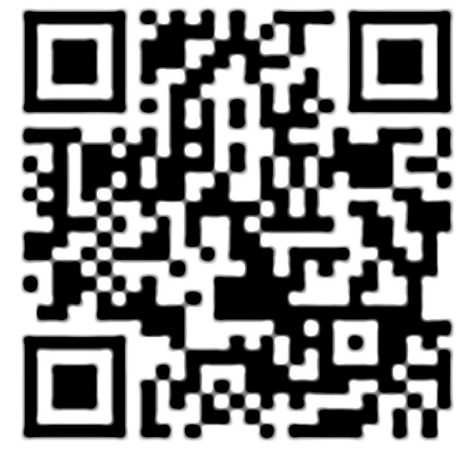

Flashcode to the Group of EFC on Linkedln 